\title{
Cyclical Nurse Scheduling in Shah Alam Hospital Using Goal Programming
}

\author{
Diana Sirmayunie Mohd Nasir ${ }^{1 *}$, Nurul Hanani Che Bahrom ${ }^{2}$, Nor Hayati Shafii ${ }^{3}$, Nor Azriani Mohamad \\ Nor $^{4}$ \\ ${ }^{1,2,3,4}$ Faculty of Computer and Mathematical Sciences, \\ Universiti Teknologi MARA Perlis Branch, Arau Campus, 02600 Arau, Malaysia
}

Corresponding author: * dianasirmayunie@uitm.edu.my

Received Date: 6 January 2021

Accepted Date: 27 January 2021

Published Date: 28 February 2021

\section{HIGHLIGHTS}

- We concentrate on the issue of scheduling nurses' shifts in a hospital.

- A real case study in Coronary Care Unit (CCU) at Shah Alam hospital is considered.

- To generate the schedule, LINGO program just takes a short time.

- All nurses experience the satisfactory and unsatisfactory schedule set by the proposed scheduling.

\begin{abstract}
A shift work schedule is extremely important to obtain the optimum result of work allocation since it involves 24 hours of continuous services. Every nurse could not avoid shift work schedule since their services are very important towards the patients in the hospital. The major objective of the study is to propose a cyclical nurse scheduling in the Coronary Care Unit (CCU) at Shah Alam hospital using Goal Programming. It is to help the head nurse to spend less effort on building new schedules periodically and increase the satisfaction among nurses by providing fairness towards their schedules. There were nine hard constraints and three soft constraints for the nurse scheduling model. The results presented the optimal solution where all goals were achieved thus, it provided a fair schedule for 15 nurses in 15 days. Then, the schedule pattern was rotated among nurses based on the 15 schedules set in 225 days. The first schedule set will be used by the nurse for the first 15 days, then will be continuously rotated for another 15 days until all the nurses reached and experienced every 15 sets of the schedule. The schedule was generated using LINGO software which it took a short time to solve the problem.
\end{abstract}

Keywords: cyclical scheduling; shift work; nurse; constraints; goal programming.

\section{INTRODUCTION}

A person who is trained to give care or provide help to people who are sick or injured is called a nurse. Nurses ordinarily played out their obligation in each department in the hospital such as emergency department, specialist trauma center and furthermore specialist units such as Cardiology or Coronary Care Unit (CCU), Intensive Care Unit (ICU) and numerous more (Boyd, 2017). CCU nurse scheduling offers a 
great deal of testing because the qualified nurses need to track the vital patient for 24 hours. Nurse scheduling subsequently requires shift work that any nurse needs to perform successfully.

Shift works is an employment practice for organizations that provide services and produces output 24 hours (Begani,2013). In order to make work easier and more efficient in organization, scheduling is needed. Cylical schedule is a set of work designs that are rotated at a specific time between employees or known as commonly scheduled for a period of four to six weeks and will repeat one period after another. According to Wang et al.(2014), the advantage of cyclical shedule is that it holds fixed and militarized properties.

The head nurse, with the aid of Microsoft Excel software, is currently manually designing the nurse schedule and had to spend five or six days to complete the schedule. If there is a demand from nurses, the person who is responsible for the schedule will have to change it. In addition, unorganized scheduling of time may lead to biases among nurses where some would have to spend more time than others.If the nurse department continues to do the same styles for nursing duties, the head nurse herself will be burdened with sacrificing her time each month to construct and repair the schedule. Therefore, the purpose of the research discussed in this paper is to propose a new cyclical nurse scheduling model at Shah Alam Hospital in the Coronary Care Unit (CCU). The model is constructed through the use of goal programming, which would consider the nurse's policies as the hard constraints and the nurses' preferences as the soft constraints.

\section{RELATED WORKS}

\section{i. Topic related literature}

As our subject relates to scheduling, this section will therefore discuss about a similar related topic. Thongsanit et al. (2016) used Integer linear programming to fix the problem of nurse scheduling. The objectives are to balance the load of each shift for all nurses and to minimize the maximum deviation of the average load for each shift using mix-max objectives. A similar thought is additionally raised by (Boah, Adu, \& Osei, 2014) and (Kumar, Nagalakshmi, \& Kumaraguru, 2014) who propose the same method to solve the shift sequence for nurse scheduling to maximize the fairness of the schedule. This research illustrated how the model could illuminated the nurse scheduling. The ideal arrangement was acquired utilizing Excel Solver and the linear programming model productively use the time and exertion likewise balance the workload of nurses. Additional technique used in scheduling problem is the Genetic Algorithm (Tsai \& Lee, 2010). The research was conducted to optimize the nurse scheduling problem with two-stage mathematical programming model. LINGO and MATLAB were used in these two stages. Next to that, binary fuzzy goal programming was applied when there is where a decision maker wants to decide (Chang, 2006). This model was used to solve uncertainties that exist at pediatrics emergency unit in Konya, Turkey (Cetin \& Sarucan, 2015).

\section{ii. The Methodology Related Literature}

Since this study used goal programming as method, this segment of writing will zero in on the paper led with a similar technique. Various objectives could be dealt with by this technique as it aims to decrease the deviation between the desired goals and the realized results, not optimizes the objectives directly (Mathirajan \& Ramanathan, 2007). Several applications for goal programming were done, for example, in project management problem, optimization, transportation problem and others. Yahia-Berrouiguet \& Tissourassi(2015) were proposed a goal programming model in the project management at SEROR's

Copyright $\odot 2021$ UiTM Press. This is an open access article under the CC BY-NC-SA

(https://creativecommons.org/licenses/by-nc-sa/4.0//) 
company in Algeria. As a result, the proposed model reveals satisfactory levels of achievement for managing three projects with preemptive goals. Also, Liang (2010) was applied this method to optimize the duration time and the crash time tolerance in every activity in the project with references to direct costs, indirect costs and constraints of available budget.

Moreover, transportation problem also can be solved using goal programming model by minimizing the transportation cost (Kommerce, Babu, \& Madhubala, 2011). This was supported by Zangiabadi \& Maleki (2007), who determined an optimal compromise solution for multi objectives transportation problems by minimizing the negative deviation from 1 . Other than that, this method be able to optimize the production of raw materials, machine usage and cost. Anggraeni et al. (2015) proposes a goal programming technique to determine combinations of number of products according to multiple objectives. The result concluded that all the goals in the proposed model were achieved.

There are several previous studies that have been conducted to solve staff scheduling problem using goal programming. Jenal et al.(2011) proposed a goal programming method to solve the cyclical nurse scheduling problem specially to help the head nurse reduce her effort on constructing new schedules periodically. The result provided an optimal solution with high satisfaction for both hospital and nurses. Then, the research was supported by Agyei, Obeng-denteh, \& Andaam(2015). The study presented a 0-1 goal programming model to solve the nurse scheduling at Outpatient Department (OPD). The findings showed that the technique created a schedule with a workload balance, a fair distribution of consecutive night duties, and fulfilled all the preferences of the nurse. Meanwhile, Mat Saleh, S. S., Ali, N., \& Jamian, N. H. (2019) implemented a goal programming for the allocation of teaching hours among academic staff. It was found that the model proposed was appropriate to be used for teaching load allocation in the department. Seeing as it was more suitable for the problem where multiple goals were considered, this paper has agreed to change goal programming. Furthermore, it is effective in cases where the various objectives re clashing and cannot all be fully accomplished.

\section{METHODOLOGY}

To construct a cyclical schedule for nurses at the Coronary Care Unit (CCU) at Shah Alam hospital, this study uses the goal programming model. To run the goal programming, Lingo software was used. The new manual schedule was received from the nursing head, consisting of 15 nurses over 15 working days. This schedule includes three 24-hour changes, including seven morning shifts (7:00 a.m. to 2:00 p.m.), seven evening shifts (2:00 p.m. to 9:00 p.m.), and ten-night shifts on duty (9.00 pm to $7.00 \mathrm{pm})$. The proposed model assumed the policies of a nurse as the hard constraints, while the preferences of the nurses as the soft constraints.

\section{i. Construct the variables}

The following notations are used to formulate the model:

$\mathrm{n} \quad=$ number of days, $\mathrm{n}=15$ days.

$\mathrm{m}=$ number of nurses, $\mathrm{m}=15$.

$\mathrm{i} \quad=$ index represent days, $\mathrm{i}=1,2, \ldots, \mathrm{n}$

$\mathrm{k}=$ index represent the nurses, $\mathrm{k}=1,2, \ldots, \mathrm{m}$

$\mathrm{A}_{\mathrm{i}} \quad=$ number of nurses for morning shift for the day, $\mathrm{i}=1,2, \ldots, \mathrm{n}$

$\mathrm{B}_{\mathrm{i}}=$ number of nurses for evening shift for the day, $\mathrm{i}=1,2, \ldots, \mathrm{n}$ 
$\mathrm{C}_{\mathrm{i}} \quad=$ number of nurses for night shift for the day, $\mathrm{i}=1,2, \ldots, \mathrm{n}$

$\mathrm{S}_{\mathrm{i}} \quad=$ number of nurses that is off on duty at the day, $\mathrm{i}=1,2, \ldots, \mathrm{n}$

In this case $A_{i, k}, B_{i, k}$ and $C_{i, k}$ are decision variables, which :

$$
\begin{aligned}
& Q A_{i, k}=\left\{\begin{array}{l}
1 \text { Nurses } k^{\text {th }} \text { that assigned morning shift for day } i . \\
0 \text { otherwise }
\end{array}\right. \\
& Q B_{i, k}=\left\{\begin{array}{l}
1 \text { Nurses } k^{\text {th }} \text { that assigned evening shift for day } i . \\
0 \text { otherwise }
\end{array}\right. \\
& Q C_{i, k}=\left\{\begin{array}{l}
1 \text { Nurses } k^{\text {th }} \text { that assigned night shift for day } i . \\
0 \text { otherwise }
\end{array}\right. \\
& Q S_{i, k}=\left\{\begin{array}{l}
1 \text { Nurses } k^{\text {th }} \text { that assigned day off for day } i . \\
0 \text { otherwise }
\end{array}\right.
\end{aligned}
$$

\section{ii. Hard Constraints}

Nine hard constraints suggested by the management of CCU Shah Alam Hospital are met by the cyclical schedule, considered as compulsory constraints, as shown below:

Set 1: Defines the minimum number of required nurses, as equations (1) - (3) below.

$$
\begin{aligned}
& \sum_{k=1}^{m} Q A_{i, k} \geq A_{i}, I=1,2, \ldots, n \\
& \sum_{k=1}^{m} Q B_{i, k} \geq B_{i}, I=1,2, \ldots, n \\
& \sum_{k=1}^{m} Q C_{i, k} \geq C_{i}, I=1,2, \ldots, n
\end{aligned}
$$

Set 2: Provides that each nurse works only one shift a day.

$$
Q A_{i, k}+Q B_{i, k}+Q C_{i, k}+Q S_{i, k}=1, i=1,2 . ., n \text { and } k=1,2, \ldots, m
$$

Set 3: Each nurse who deals with a night shift is absolved from working at the morning and evening shifts of the following day in the accompanying way:

$$
Q C_{i, k}+Q A_{i+1, k}+Q B_{i+1, k} \leq 1, i=1,2 . ., n-1 \text { and } k=1,2, \ldots, m
$$

Set 4: Defines the separate working days as follows: (off-on-off)

$$
Q S_{i, k}+Q A_{i+1, k}+Q B_{i+1, k}+Q C_{i+1, k}+Q S_{i+2, k} \leq 2, i=1,2 . ., n-1 \text { and } k=1,2, \ldots, m
$$


Set 5: To ensure that every nurse who works three full consecutive days of the night is given a day off on the following day, as established by the corresponding conditions (7)-(11) are used:

$$
\begin{gathered}
Q C_{i, k}+Q C_{i+1, k}+Q C_{i+2, k}+Q S_{i+3, k}+Q S_{i+4, k}=5, i=1 \text { and } k=1,2,3 \\
Q C_{i, k}+Q C_{i+1, k}+Q C_{i+2, k}+Q S_{i+3, k}+Q S_{i+4, k}=5, i=4 \text { and } k=4,5,6 \\
Q C_{i, k}+Q C_{i+1, k}+Q C_{i+2, k}+Q S_{i+3, k}+Q S_{i+4, k}=5, i=7 \text { and } k=7,8,9 \\
Q C_{i, k}+Q C_{i+1, k}+Q C_{i+2, k}+Q S_{i+3, k}+Q S_{i+4, k}=5, i=10 \text { and } k=10,11,12 \\
Q C_{i, k}+Q C_{i+1, k}+Q C_{i+2, k}=5, i=13 \text { and } k=13,14,15
\end{gathered}
$$

Set 6: Define each nurse who works for a maximum of 6 consecutive days as follows:

$$
Q S_{i, k}+Q S_{i+1, k}+Q S_{i+2, k}+Q S_{i+3, k}+Q S_{i+4, k}+Q S_{i+5, k} \geq 1, i=1,2 . ., n-5 \text { and } k=1,2, \ldots, m
$$

Set 7: Warrants to ensure that each nurse for each schedule works from 9 to 11 days. Here, conditions (13)(14) are used:

$$
\begin{aligned}
& \sum_{i=1}^{n}\left(Q A_{i, k}+Q B_{i, k}+Q C_{i, k}\right) \geq 9, k=1,2, \ldots, m \\
& \sum_{i=1}^{n}\left(Q A_{i, k}+Q B_{i, k}+Q C_{i, k}\right) \leq 11, k=1,2, \ldots, m
\end{aligned}
$$

Set 8: To ensure evening shift to a minimum constitutes at least $20 \%$ of total working days.

$$
\sum_{k=1}^{n} Q B_{i, k} \geq 2, i=1,2, \ldots, n
$$

Set 9: To ensure morning shift to a minimum constitutes at least $30 \%$ of total working days.

$$
\sum_{k=1}^{n} Q A_{i, k} \geq 3, i=1,2, \ldots, n
$$

\section{iii. Soft Constraints}

The references constraints expressed by the nurses, could be optional and an ecceptable planning could violate the some of them. There are three soft constraints in this study. First of both, all nurses have a comparable measure of the overall unfinished task at hand. Next, to reach a goal that prohibits nurses working on the evening shift from working on the morning shift or the night shift for the next day. Finally, the limitation is that a morning shift is not preceded by an evening shift or the next day by a night shift. In order to analyze whether or not each goal would be achieved, the objective was established according to the soft constraints. The mathematical model with the deviation variable for these three objectives is as follows:

Goal 1 : To ensure all nurses have a similar measure of complete outstanding task at hand.

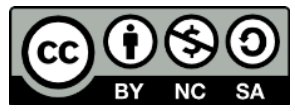




$$
\sum_{i=1}^{n}\left(Q A_{i, k}+Q B_{i, k}+Q C_{i, k}\right)+\eta 1_{k}-\rho 1_{k}=10, k=1,2, \ldots, m
$$

Goal 2: Avoid working in an evening shift followed by a morning shift or night shift on the next day.

$$
Q B_{i, k}+Q A_{i+1, k}+Q C_{i+1, k}+\eta 2_{k}-\rho 2_{k}=1, i=1,2, \ldots, n-2 \text { and } k=1,2, \ldots, m
$$

Goal 3: Avoid working in a morning shift followed by an evening shift or night shift the next day.

$$
Q A_{i, k}+Q B_{i+1, k}+Q C_{i+1, k}+\eta 3_{k}-\rho 3_{k}=1, i=1,2, \ldots, n-2 \text { and } k=1,2, \ldots, m
$$

Where $\eta 1_{k}, \eta 2_{k}, \eta 3_{k}$ are negative deviation and $\rho 1_{k}, \rho 2_{k}, \rho 3_{k}$ are positive deviation variables.

Thus, the preemptive goal programming objectives are presented as follows:

$$
\operatorname{Minimize}\left(\sum_{k=1}^{n}\left(\eta 1_{k}+\rho 1_{k}\right), \sum_{i=1}^{n-2} \sum_{k=1}^{m} \rho 2_{k}, \sum_{i=1}^{n-2} \sum_{k=1}^{m} \rho 3_{k}\right)
$$

\section{FINDINGS AND DISCUSSIONS}

To restate, Lingo software has been used to run the goal programming model. As stated before, the schedule of 15 days and 15 nurses was planned to ease the cyclical schedule development process. The schedule of working days and days off within 15 days of the planning period created from the model is shown in table 1. The schedule fulfilled all the hard and soft constraints where all goals were fulfilled. When analyzing the schedules, goal 1 is achieved where every nurse has an equal number of working days within 15 days. Simultaneously, Goal 2 and Goal 3 mean to confine morning and evening shift from being followed by other shift for the following day are likewise accomplished. As can be seen, no shift after morning or evening shift is characterized by an off day for the next morning or evening.

Table 1: The scheduling model using goal programming

\begin{tabular}{|c|l|l|l|l|l|l|l|l|l|l|l|l|l|l|l|}
\hline \multirow{2}{*}{ Nurse } & \multicolumn{19}{|c|}{ (1 } & 2 & 3 & 4 & 5 & 6 & 7 & 8 & 9 & 10 & 11 & 12 & 13 & 14 & 15 \\
\hline K1 & N & N & N & & & & M & M & M & & E & E & E & & M \\
\hline K2 & N & N & N & & & M & M & & E & E & E & E & & & M \\
\hline K3 & N & N & N & & & & E & E & E & E & & M & M & M & \\
\hline K4 & E & E & & N & N & N & & & M & M & M & & & E & E \\
\hline K5 & M & & & N & N & N & & & M & M & M & & E & E & E \\
\hline K6 & M & & & N & N & N & & & E & E & E & E & & M & M \\
\hline K7 & & M & M & M & M & & N & N & N & & & & E & E & E \\
\hline K8 & E & E & & M & M & & N & N & N & & & M & M & & E \\
\hline K9 & E & E & E & E & & & N & N & N & & & M & M & M & \\
\hline K10 & M & M & & E & E & & E & E & & N & N & N & & & M \\
\hline K11 & M & M & M & & E & E & E & E & & N & N & N & & & \\
\hline K12 & M & & E & E & & M & M & M & & N & N & N & & & E \\
\hline K13 & & & M & M & M & M & & E & E & E & & & N & N & N \\
\hline
\end{tabular}




\begin{tabular}{|l|l|l|l|l|l|l|l|l|l|l|l|l|l|l|l|}
\hline K14 & & & E & E & E & E & & M & M & M & & & N & N & N \\
\hline K15 & & & & E & E & E & & M & M & M & M & & N & N & N \\
\hline
\end{tabular}

$\mathrm{M}=$ Morning, E= Evening, $\mathrm{N}=$ Night

Table 2: Summary of the number of shift for every nurses

\begin{tabular}{|l|c|c|c|c|c|}
\hline Nurse & Morning & Evening & Night & Off & $\begin{array}{c}\text { Total of } \\
\text { working days }\end{array}$ \\
\hline K1 & 4 & 3 & 3 & 5 & 10 \\
\hline K2 & 3 & 4 & 3 & 5 & 10 \\
\hline K3 & 3 & 4 & 3 & 5 & 10 \\
\hline K4 & 3 & 4 & 3 & 5 & 10 \\
\hline K5 & 4 & 3 & 3 & 5 & 10 \\
\hline K6 & 3 & 4 & 3 & 5 & 10 \\
\hline K7 & 4 & 3 & 3 & 5 & 10 \\
\hline K8 & 4 & 3 & 3 & 5 & 10 \\
\hline K9 & 3 & 4 & 3 & 5 & 10 \\
\hline K10 & 3 & 4 & 3 & 5 & 10 \\
\hline K11 & 3 & 4 & 3 & 5 & 10 \\
\hline K12 & 4 & 3 & 3 & 5 & 10 \\
\hline K13 & 4 & 3 & 3 & 5 & 10 \\
\hline K14 & 3 & 4 & 3 & 5 & 10 \\
\hline K15 & 4 & 3 & 3 & 5 & 10 \\
\hline
\end{tabular}

Table 2 shows the summary for the number of shifts for each nurse. It shows that goal 1 was achieved where all nurses have the same 10 working days in the schedule. Plus, all nurses have the same number of off days and night shift which are 5 and 3 days respectively.

Table 3: Cyclical scheduling sets of the nurses in 225 days

\begin{tabular}{|c|c|c|c|c|c|c|c|c|c|c|c|c|c|c|c|}
\hline \multirow[b]{2}{*}{ Nurse } & \multicolumn{15}{|c|}{ SET } \\
\hline & 1 & 2 & 3 & 4 & 5 & 6 & 7 & 8 & 9 & 10 & 11 & 12 & 13 & 14 & 15 \\
\hline K1 & 1 & 2 & 3 & 4 & 5 & 6 & 7 & 8 & 9 & 10 & 11 & 12 & 13 & 14 & 15 \\
\hline K2 & 2 & 3 & 4 & 5 & 6 & 7 & 8 & 9 & 10 & 11 & 12 & 13 & 14 & 15 & 1 \\
\hline K3 & 3 & 4 & 5 & 6 & 7 & 8 & 9 & 10 & 11 & 12 & 13 & 14 & 15 & 1 & 2 \\
\hline K4 & 4 & 5 & 6 & 7 & 8 & 9 & 10 & 11 & 12 & 13 & 14 & 15 & 1 & 2 & 3 \\
\hline K5 & 5 & 6 & 7 & 8 & 9 & 10 & 11 & 12 & 13 & 14 & 15 & 1 & 2 & 3 & 4 \\
\hline K6 & 6 & 7 & 8 & 9 & 10 & 11 & 12 & 13 & 14 & 15 & 1 & 2 & 3 & 4 & 5 \\
\hline K7 & 7 & 8 & 9 & 10 & 11 & 12 & 13 & 14 & 15 & 1 & 2 & 3 & 4 & 5 & 6 \\
\hline K8 & 8 & 9 & 10 & 11 & 12 & 13 & 14 & 15 & 1 & 2 & 3 & 4 & 5 & 6 & 7 \\
\hline K9 & 9 & 10 & 11 & 12 & 13 & 14 & 15 & 1 & 2 & 3 & 4 & 5 & 6 & 7 & 8 \\
\hline K10 & 10 & 11 & 12 & 13 & 14 & 15 & 1 & 2 & 3 & 4 & 5 & 6 & 7 & 8 & 9 \\
\hline K11 & 11 & 12 & 13 & 14 & 15 & 1 & 2 & 3 & 4 & 5 & 6 & 7 & 8 & 9 & 10 \\
\hline
\end{tabular}




\begin{tabular}{|l|l|l|l|l|l|l|l|l|l|l|l|l|l|l|l|}
\hline K12 & 12 & 13 & 14 & 15 & 1 & 2 & 3 & 4 & 5 & 6 & 7 & 8 & 9 & 10 & 11 \\
\hline K13 & 13 & 14 & 15 & 1 & 2 & 3 & 4 & 5 & 6 & 7 & 8 & 9 & 10 & 11 & 12 \\
\hline K14 & 14 & 15 & 1 & 2 & 3 & 4 & 5 & 6 & 7 & 8 & 9 & 10 & 11 & 12 & 13 \\
\hline K15 & 15 & 1 & 2 & 3 & 4 & 5 & 6 & 7 & 8 & 9 & 10 & 11 & 12 & 13 & 14 \\
\hline
\end{tabular}

A cyclical schedule is the schedule that is repeated after a predetermine time (Belien, Demeulemeester, \& Cardeon, 2009). Table 3 shows the cyclical nurse scheduling will rotate equally where the reasonableness factor was turned decently among nurses. Based on the result, each nurse will have 15 sets of schedules for 225 days. Then they meet the first schedule's pattern again. Schedule of 15 days was selected because the similar set for each nurse can be reached for the following 15 days without abusing both hard and soft constraints. By performing the proposed cyclical scheduling method, all nurses experience the satisfactory and unsatisfactory schedule set and this leads to an overall higher satisfaction among them.

\section{CONCLUSION AND RECOMMENDATIONS}

Develop the nurse scheduling with LINGO software using goal programming has demonstrated its ability to produce schedule by thinking about the hard and soft constraints in the formulation. Additionally, cyclical scheduling eases the burden of the head nurse in constructing new schedule. Discoveries of the study indicate that all goals are achieved. Specifically, an efficient schedule had the option to be created dependent on hard and soft constraints set for the model. Furthermore, with this cyclical scheduling, it gives nurses more power over their work life since they know the sort of move plan ought to emphatically influence their action satisfaction.

For further research, it is possible to consider other features such as maternity leave, days off on weekends and public holiday. Majority of the nurses are female and married, hence, maternity leave should be one of the aspects needed to improve the model. Furthermore, this study can be improved by adding other factors in the schedule like nursing expertise and skills. This can improve the management of health care in the hospital and provides a better service to the patients.

\section{ACKNOWLEDGMENTS}

The authors wish to offer their thanks and gratefulness to the Head Nurse of the Coronary care Unit (CCU) at Shah Alam Hospital for supporting this study by permitting us to use their data.

\section{REFERENCES}

Agyei, W., Obeng-denteh, W., \& Andaam, E. A. (2015). Modelling Nurse scheduling problem using 0-1 goal programming: A case study of Tafo Government Hospital, Kumasi Ghana. International Journal of Scientific and Technology Research, 4, 5-10. 
Anggraeni, W., Vinarti, R. A., Tyasnurita, R., \& Permatasari, J. (2015). Production planning optimization using goal programming method in Habibah Busana. Journal of Advanced management Science, 270275 .

Begani, R. K., Begani, A. Z., So'on, V., \& Pokasui, K. (2013). Impact of shift work amongst security guards in Madang. Contemporary PNG studies, 18, 98-116.

Belien, J., Demeulemeester, E., \& Cardeon, B. (2009). a decision support system for cyclic master surgery scheduling with multiple objectives. Journal of scheduling, 12(2), 147-161.

Boah, D. K., Adu, I. K., \& Osei, P. A. (2014). Nurse Scheduling at Navrongo war Memorial Hospital in Ghana using linear programming. Jornal of Innovative Technology and Education, 1, 25-33.

Boyd, C. (2017). What is different between a CCU and ICU? Retrieved september 30, 2017, from azcentral: https://healthyliving.azcentral.com/what-is-the-difference between-a-ccu-icu-12523286.html

Cetin, E., \& Sarucan, A. (2015). Nurse Scheduling using Binary Fuzzy Goal Programming. Modeling,Simulation and aApplied Optimization (ICMSAO), 1-6.

Chang, C. T. (2006). Binary Fuzzy Goal Programming. European Journal of Operational Research, 18, 29-37.

Jenal, R., Ismail, W. R., Yeun, L. C., \& Oughalime, A. (2011). A cyclical nurse schedule using goal programming. ITB Journal of Sciences, 43, 151-164.

Kommerce, S. M., Babu, G. R., \& Madhubala, M. (2011). Goal Programming problem for Transportation problem. International Journal of ComputerScience and Information Technology, 4, 43-48.

Kumar, B. S., Nagalakshmi, G., \& Kumaraguru, S. (2014). A shift sequence for nurse scheduling using linear programming problem. Journal of Nursing and Health Science, 3(6), 24-28.

Liang, T. F. (2010). Applying Fuzzy goal programming to project management decisions with multiple goals in uncertain environment. Expert Sustems with Applications, 37, 8499-8507.

Mathirajan, M., \& Ramanathan, R. (2007). A (0-1) goal programming model for scheduling the tour of a marketing executive. European Journal of Operation Research, 179, 54-66.

Mat Saleh, S. S., Ali, N., \& Jamian, N. H. (2019). Team Teaching Load using Linear Programming. Journal of Computing Research and Innovation, 4(1), 8-15.

Thongsanit, K., Kantangkul, K., \& Nithimethirot, T. (2016). Nurse's shift balancing in nurse scheduling problem. Silpakorn University Science and Technology Journal, 10, 43-48.

Tsai, C. C., \& Lee, C. J. (2010). Optimization of nurse scheduling problem with a two-stage mathematical programming model. Asia Pacific management Review, 15(4), 503-516. 
Wang, S. P., Hsieh, Y. K., Zhuang, Z. Y., \& Ou, N. C. (2014). Solving an Outpatient nurse scheduling problem by binary goal programming. Journal of Industrial and Production Engineering, 31, 41-50.

Yahia-Berrouiguet, A., \& Tissourassi, K. (2015). Application of goal programming model for allocating time and cost in project management:A case study from the company of construction SEROR. yugoslav Journal of operation Research, 25(2), 283-289.

Zangiabadi, M., \& Maleki, H. R. (2007). Fuzzy Goal programming for multiobjective transportation problems. Journal of Applied mathematics and Computing, 24, 449-460. 